\title{
Research on Tesla's Price Strategy in China
}

\author{
Shuwen Qin ${ }^{1, a,{ }^{*}, \dagger}$, Guangzheng $\mathrm{Wu}^{2, \mathrm{~b}, *}, \dagger$ \\ ${ }^{1}$ Jiangxi University of Finance and Economics, Business Administration faculty, Nanchang, Jiangsu, China \\ ${ }^{2}$ Queen Mary University of London, Corporate finance faculty, London, The United Kingdom

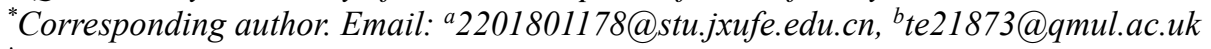 \\ †These authors contributed equally.
}

\begin{abstract}
In 2021, Tesla, as the leader of electric vehicles, is very common in China. Traditional automobile price research shows that automobiles as a commodity have sufficient price elasticity of demand. However, early research also shows that electric vehicles do not have sufficient price elasticity of demand as a new type of vehicle. Starting from the price elasticity of demand, this paper analyzes Tesla's price strategy in China from three dimensions: theoretical model, econometric test, and case analysis. The research on Tesla's sales data through the ARIMA model and Linear Regression shows that Tesla's products have a significant price elasticity of demand, which is different from previous conclusions. The case also shows that price is Tesla's most effective weapon as a market entrant, and price reduction has brought Tesla a strong entry effect. However, the original incumbents in the Chinese market have been impacted by the market, failing to seize the advantages of time and geographical location to play a very good preventive effect.
\end{abstract}

Keywords: Tesla, Skimming Pricing, Entrant, Incumbent, Price Elasticity of Demand, Entry Blocking Effect

\section{INTRODUCTION}

With the development of the world economy and the acceleration of economic globalization, the use of nonrenewable resources such as oil is increasing, bringing about resource scarcity. At the same time, the harm of global warming, air pollution and other phenomena has increased dramatically. Governments urgently need renewable and environmentally friendly energy to replace oil, and more environmentally friendly electric vehicles have become a trend. Globally, in 2020, the global sales of new energy vehicles were 2.987 million, $31.8 \%$ and $0.3 \%$, accounting for $4 \%$ of the global automobile market, $31.8 \%$ and $0.3 \%$. The average sales growth rate of new energy vehicles exceeded $42 \%$. However, due to technical barriers, electric vehicles face the defects of insufficient endurance, difficult charging, and high price, and the price of electric vehicles in the market is generally high. There has been a situation that it is not popular [1].

China strongly supports the development of the electric vehicle industry and has successively issued policies such as the Notice on the Pilot Subsidies for Private Purchase of New Energy Vehicles and the 14th Five-Year Plan to provide tax incentives for the development of electric vehicles, as well as financial and policy support for enterprises to carry out relevant infrastructure construction [2].

Tesla, founded in 2003, as the benchmark and representative of high-end electric vehicle enterprises, has formulated different price strategies in three different stages through the price strategy of skimming pricing, from 734000 yuan in China at the beginning to the price adjustment of Tesla many times now, the price of new products has been as low as 271000 yuan, which has become a product that most families can consume. At the same time, it uses the positioning theory to establish a good image in the hearts of consumers and is favored by the vast number of consumers.

Therefore, as a foreign brand, how does Tesla occupy the Chinese market step by step? What role does its price strategy play? What is the secret?

\section{LITERATURE REVIEW}

Tesla has become the benchmark and representative of high-end electric vehicle enterprises in its early development. In this process, Tesla has become an outlier of automobile enterprises. There is no public relations, no advertising, but it seems that everyone has heard of Tesla. In the process, Tesla's price is extremely high, which seems to be the exclusive toy of Silicon Valley's rich elite, but with the development of these 
years. Tesla has become ubiquitous as prices have become more affordable. In this process, both the threestep strategy proposed by Musk Tesla at the beginning and the pricing changes of Tesla show obvious characteristics of skimming pricing. Philip Kotler and Gary Armstrong put forward skimming pricing in Principles of Marketing and roughly divided it into two stages. In the first stage, "the price of the product is set very high in the early stage of the product life cycle to obtain the maximum profit and recover the investment as soon as possible."? The second phase of skimming pricing "reduces the price over time, allowing the product to enter new markets with greater flexibility" [3]. In the early days, In the first stage of skimming pricing, Tesla recovered its initial investment through high pricing and established the image of high price and laid a solid foundation for consumer identity in the later stage.

The so-called consumer identity is based on the Fishbein model proposed by American scholar Fishbein as early as 1963. The consumer's attitude towards consumer goods is the embodiment of self-awareness, and consumers make self-classification according to the consumer group and affect their consumption attitude, and have a herd mentality [4]. As a result, the high pricing and the existing consumer population of Tesla at that time gave sufficient theoretical support to consumers eager to flaunt their identity by buying Tesla, which was a major benefit of the first stage of skimming pricing, in addition to the rapid recovery of investment. At the same time, given the positioning theory put forward by the famous American marketing experts Ai Rees and Jack Trout, positioning is the core point of view. In the positioning theory, the marketing strategy of Reese Company is expressed concisely and clearly, and then the positioning viewpoint is introduced into the marketing theory. Positioning theory emphasizes the importance of product positioning to determine the target customers. To ensure that the product has real value for the target population [5]. Currently, the customer portrait and positioning of Tesla, which is in the early stage of skimming pricing, are becoming clearer and clearer, "the elite of the Internet era who love environmental protection and are keen to experience new things". Currently, Tesla has been advancing to open the market under the strategy of high pricing. According to the principle of economics, high pricing often means relatively low sales. This paper will also study Tesla's price demand elasticity from traditional economic price demand elasticity. This means that to expand Tesla's profit scale further, it is necessary to expand production and sales. So, when the time came to 2016, With the launch of Tesla's Gigafactory plan, the price reduction plan has come, which also marks the second stage of Tesla's skimming pricing strategy, and the sales of the relatively cheap Tesla Model 3 rose sharply. According to 1996, Philip
Kotler, a marketing expert, put forward the famous theory of customer delivered value: the difference between the total cost of customers and the total value of customers [6]. At the beginning of price reduction, Tesla's identity benefit can get more delivered value from Tesla with lower price. However, with the price reduction of Tesla and a series of public relations events in the Chinese market, Tesla has become more and more popular. The effect of blindly reducing prices is not entirely beneficial. Tesla's transfer value is much lower than in the past.

According to the traditional $4 p$ theory [7] put forward by McCarthy in 1960, price is an important part of its market success, while according to the 4C strategy [8] put forward by Lauterbur in 1990, Tesla has done a good job in customer purchase convenience, saving costs, and reducing pricing, but neglected customer communication. So, whether to reduce the price or not. And what role did the past price reduction strategy play. From the United States to China, when Tesla faces a new market like China as a new entrant, the market share of the traditional market incumbents is squeezed. Faced with this similar situation, this paper studies entry prevention from game theory and establishes simultaneous equations models for 26 different industries. Masson and Shaana found a significant positive correlation between overproduction and pricecost margin, and the price reduction brought by overproduction can effectively prevent entrants from seizing the market, but vice versa, entrants, can also use excess capacity as a weapon to enter. While under the setting of single incumbent, single entrant and single period [9], Fudenberg and Tirole's game proves through two stages that the equalization of payments and dissipative rents make the incumbent's commitment to preventing entry by capacity investment unreliable [10]. Yang and Anderson further prove that the ability of commitment value will be reduced if the output is lower than the capacity through a multi-stage game model. As a result, the reduction of operating costs will have a greater chance to gain a first-mover advantage. The above research has a special background. That is, the starting point of the research is to judge whether these behaviors are anti-competitive. The purpose is that the antitrust agencies in the United States are investigating the predatory pricing of some companies, not entirely to judge the entry prevention effect [11]. Because the existing game model is idealistic, we turn our attention to the role of demand price elasticity in entry and prevention shown by the existing data of electric vehicles. In 2017, scholars Deng Ting and Yan Junjie published articles concluding that consumers who can afford new energy vehicles consider more brands, convenience, and comfort. Price only plays a minor role. The price elasticity of new energy vehicles is small [12], but the data source of the article is up to 2015, when Tesla has not yet built a factory in Shanghai, and now 
the market situation of electric vehicles has changed, this paper will make a supplementary study on the price elasticity of demand.

Based on the above theory, this paper will construct a model of Tesla's price strategy and the effect of price strategy combined with the industrial environment and simplify Tesla's price strategy from a simplified model through a multi-angle and multi-dimensional framework model. It starts from three aspects: building model, theoretical analysis, Tesla's background, and business environment. Finally, this paper explores the internal logic of Tesla's price strategy in the process of entering the Chinese market as an entrant and challenging the incumbent and provides some enlightenment for local Chinese enterprises.

\section{BASIC SUMMARY}

\subsection{History of Tesla}

In July 2003, Tesla was founded by Mark Tappenning and Martin Eberhard. In 2004, Musk officially raised a round of financing and produced the first electric sports car in 2008, which was named Roadster. The car was designed and produced by Tesla and Lotus Engineering, Lotus Car, a British Lotus company. Roadster borrows the structure of Lotus sports car (Elise) and designs four modules of body frame, battery, battery management system and electric motor for assembly and production. In this process, Tesla, as a new entrant in the industry, borrowed existing mature products and production lines and creatively designed an open modular product architecture, successfully breaking through barriers to enter the new energy vehicle market [13].

After 2014, the outside world questioned whether Tesla had the right to sell its products, some States in the United States considered Tesla's stores illegal, and the Automobile Dealers Association opposed Tesla's direct marketing strategy. As a result, Tesla's position that it has no intention of gaining business privileges and only hopes to sell its own cars gained more support in September 2014. It also won a lawsuit against Tesla stores in the Supreme Court of Massachusetts, which was a huge step forward in Tesla's direct marketing strategy, and Musk used the victory in other state lawsuits.

In June 2014, Elon Musk published a blog post announcing that all Tesla patents could be used by other companies free of charge. Free patents allow competitors to use Tesla's breakthrough technology, promote the maturity of the electric vehicle market, help Tesla through the crisis stage, and expand the market size of electric vehicles.

In 2016, Tesla China Factory was approved. On January 7, 2019, Tesla China Factory broke ground. In
June of that year, the factory was completed, production equipment was installed, and trial production began in October. With the successful launch of the first trial vehicle, the factory was approved on January 7, 2020. On the first anniversary of the start of construction, Tesla announced the official delivery of Model 3 made in China, and Tesla entered the last step of the three-step strategy. Today, Tesla's prices are falling, and Model 3 sales are rising.

\subsection{Prerequisites for Tesla's Price Reduction}

\subsubsection{Impact of Tesla's Product Technology on Price}

The development of electric vehicles in China has a long history, and the research and development of electric vehicles in China can be traced back to the 1960s. The state has also listed electric vehicles as a key scientific research project in the "Eighth Five-Year Plan" and "Ninth Five-Year Plan" and has achieved certain results. However, limited by the technology of electric vehicles, electric vehicles are expensive. Problems such as insufficient endurance have always existed, resulting in electric vehicles becoming a "luxury" with low-cost performance [14]. By improving the technology of electric vehicles and replicating the strategy of charging piles that have been laid out abroad, Tesla has greatly improved the shortcomings of insufficient endurance and performance of electric vehicles, and at the same time, reducing the cost of electric V epiclesis has increased Tesla's overall sales and provided some room for Tesla's price reduction. Compared with traditional high-performance vehicles, Tesla's new electric vehicles are better, and Tesla's electric vehicles have gained a greater advantage in the market competition while taking advantage of its own product and technology advantages to occupying a larger market share at a lower price [15].

\subsubsection{Innovation of sales model}

Tesla adheres to the self-built marketing model, which does not distribute cars to agents like most car companies but adopts the online sales plus self-operated store model, which greatly strengthens the self-control of the end of the sales, and is an O2O model [16].

Since its founding in 2003, Tesla has operated the electric vehicle market in the United States, while maintaining a very different sales model from other automotive companies. That is, Tesla insists on selling electric vehicles directly to consumers, rather than through intermediate dealers. After entering the Chinese market in April 2014, Tesla maintained its unique sales model. At the same time, Tesla has also formulated the same price strategy for the national conditions and market conditions of different countries to treat 
consumers in different countries fairly. Compared with traditional automobile brands, Tesla has a higher price transparency, which is deeply loved by Chinese consumers and has established a good brand image for Tesla in the domestic market. Thanks to Tesla's opensource policy, allowing other electric vehicle companies to use Tesla's patented knowledge on electric vehicles has greatly promoted the rapid development of the electric vehicle industry as a whole, reduced technical barriers, and at the same time, the relatively fair technical environment has prompted enterprises to focus on technological innovation to enhance competitiveness [13]. This kind of direct marketing strategy for consumers reduces the intermediate circulation links, reduces the miscellaneous sales costs, and provides conditions for Tesla's subsequent price strategy.

\subsubsection{Impact of China's Policy Support on Tesla Price}

In recent years, with the destruction of the ecological environment and the sharp increase in resource consumption, the Chinese government has strongly supported the development of electric vehicles. With the development of electric vehicles, a few policies have been introduced to facilitate the development of $\mathrm{e}$ electric vehicles. In June 2010, The National Development and Reform Commission, the Ministry of Science and Technology, the Ministry of Finance and the Ministry of Industry and Information Technology agreed to and issued the Notice on the Pilot Implementation of Subsidies for Private Purchase of New Energy Vehicles, and five cities worked out the pilot implementation plan of subsidies for the private purchase of new energy vehicles, which granted a maximum subsidy of 60,000 yuan per electric vehicle. In addition, the government has reduced the price of electric vehicles by reducing the purchase tax and subsidizing the purchase price to attract consumers to buy electric vehicles. Many favorable policies also led Tesla to start reducing prices. In April 2020, as soon as the Notice on Improving the Financial Subsidy Policy for the Promotion and Application of New Energy Vehicles was issued, Tesla was the first to respond, reducing prices to 27 . Ten thousand yuan.

\section{ANALYSIS OF TESLA'S PRICE STRATEGY}

\subsection{Overview of Tesla's Pricing Strategy}

At the beginning of its establishment, Tesla put forward a "three-step" development strategy: first, to develop high-end, high-performance sports electric vehicles, while proving the feasibility of electric vehicles, to be "dazzling" enough to attract the first batch of targeting customers-high-income people with environmental awareness and celebrities who pay attention to public image. Especially the young talents of Silicon Valley and Hollywood stars. The second step is to develop electric vehicles with prices close to luxury brands such as Mercedes-Benz and BMW. Finally, the third step is to introduce low-cost and economical electric vehicles whose prices are acceptable to the public and can be promoted on a large scale. This process from high price to low price is in line with the definition of skimming pricing by Philip Kotler and Gary Armstrong. At present, Tesla's products on sale are Model 3 (July 2017), Model Y (March 2020), Model X (September 2015) and Model S (June 2012) in order of price. The price of new products launched by Tesla is from high to low, from far to near. Among them, the products launched at different times also show some different pricing characteristics. Among these products, Model 3 and Model $\mathrm{Y}$ is made in China. As the main products to open the Chinese market, these two products are the main skimming pricing strategy. Taking the standard endurance version as an example, according to the price on Tesla's official website, we fit the product price trend chart [Figure 1]. We can draw a more intuitive conclusion: The price strategy adopted by Tesla when entering the Chinese market is skimming pricing.

\section{2 'Tesla' price elasticity analysis}

From Tesla's earnings over the years, we can get the following chart. 


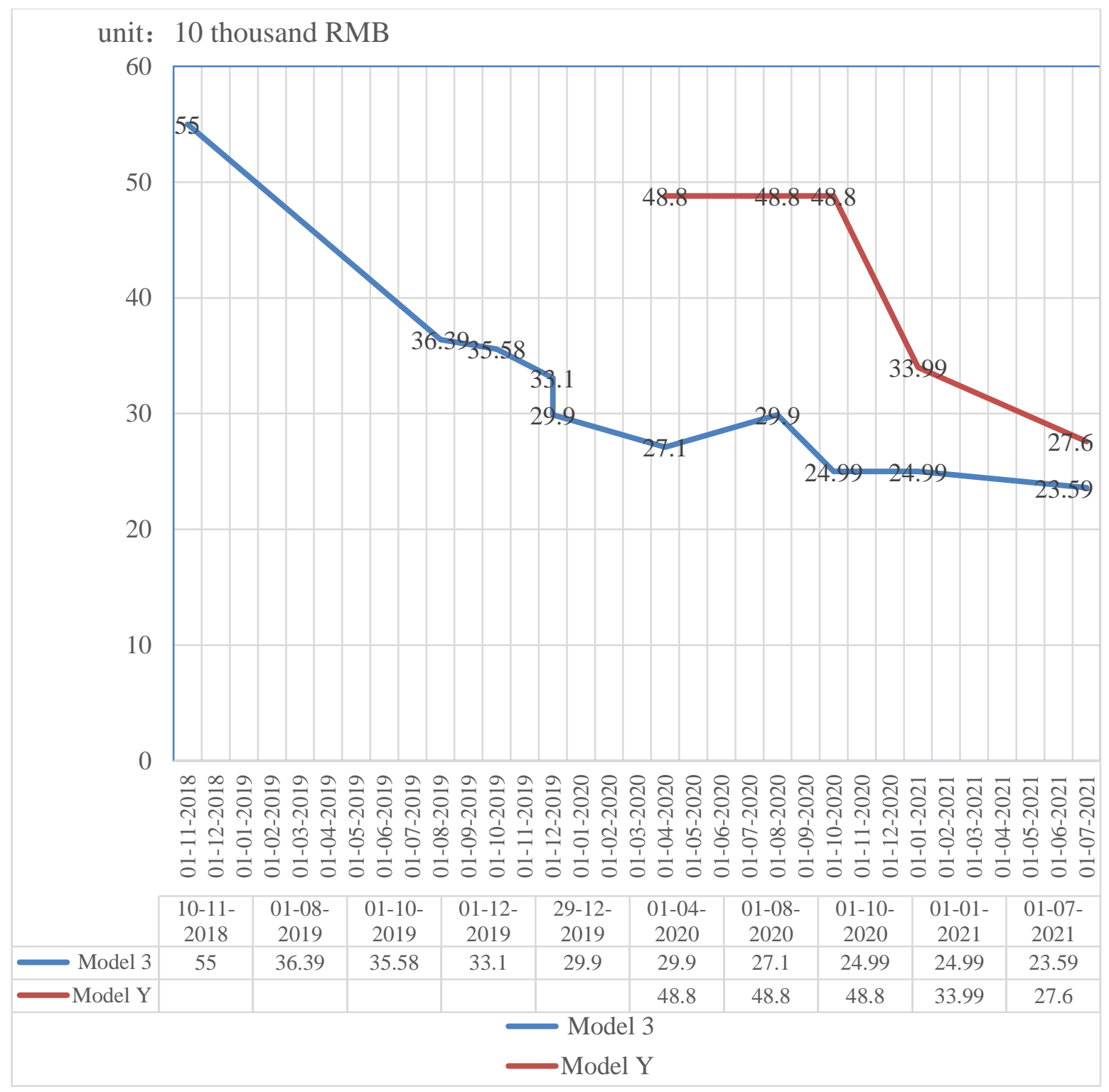

Figure 1. Price trends of Tesla products 


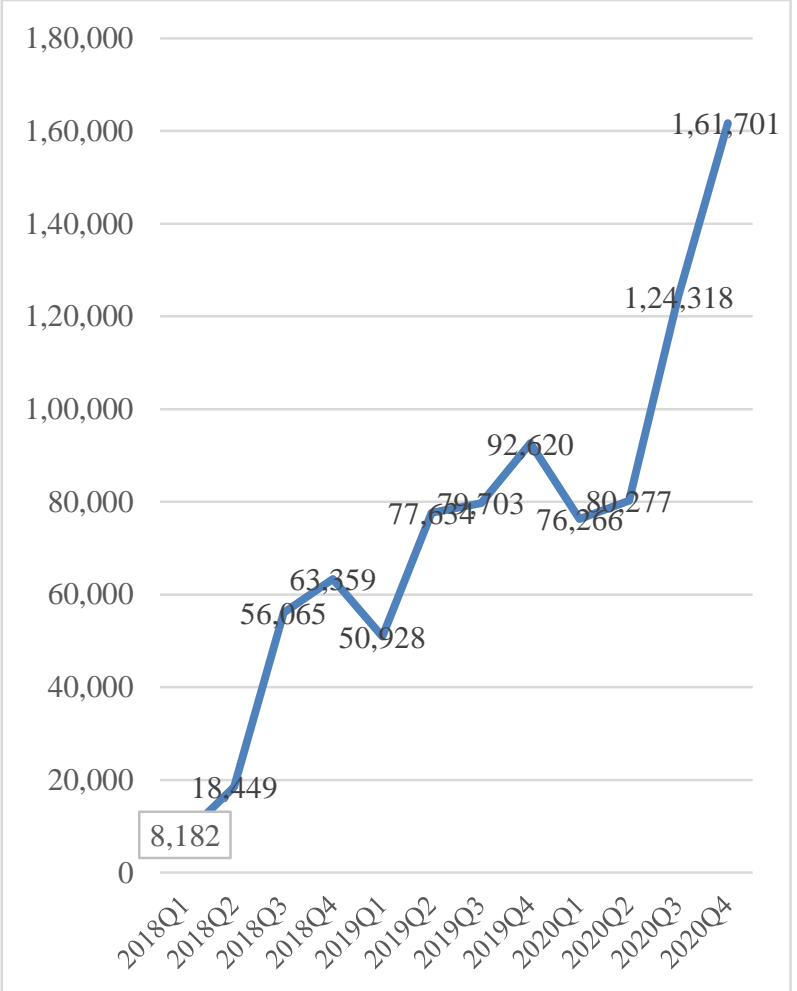

Figure 2. Sales volume of Model 3 and Model Y (unit: vehicle)

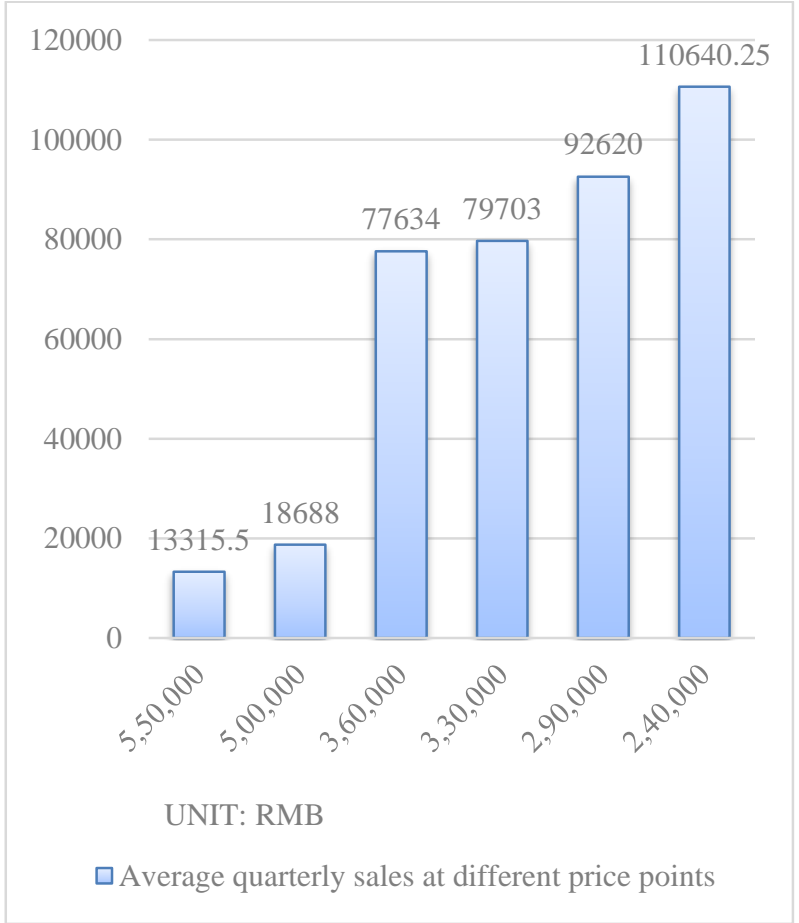

Figure 3. Average quarterly sales at different price points

Tesla officially entered China in 2013, when Tesla's main product was Model S, but at that time, Tesla had not yet realized its plan to build a factory in China. At that time, Model S was priced at $734000 \mathrm{RMB}$, which was still a luxury car for the people. The intro to the price reduction came from the official approval of the Shanghai Super Factory in 2016, when Tesla's Shanghai factory was officially put into operation in 2019. The Model 3 of the Tesla factory in Shanghai was officially put into production, as shown in Figure 1. At the same time, the price of Model 3 was greatly reduced, although the price data of Tesla since 2018 was analyzed by SPSS software according to Deng Ting and Yan Junjie [12]. It can be concluded that the significance level of price and sales volume is 0.755 , which is greater than 0.5 , indicating that there is no significant relationship. However, since the analysis of the correlation between price adjustment and sales increase is a static analysis, it is not entirely applicable to the relationship between price and sales in the automobile sales market. The effect of price on sales needs to give the market a certain reaction time, so we adopt the analysis method of reducing the time interval of analysis, taking price reduction as the node and price as the cycle. The average sales volume of each price cycle was calculated to correct the inaccuracy of the data, and the ARIMA time series model was used to move the data to the average quarterly sales volume of the same price cycle (as shown in Figure 3). After SPSS [17] analysis, the significance level was 0.001 . It shows that there is a significant correlation between sales volume and price [18].

$$
E d=-\frac{\partial Q}{\partial P} \times \frac{\left(P_{1}+P_{2}\right) \div 2}{\left(Q_{1}+Q_{2}\right) \div 2}
$$

$\frac{\partial Q}{\partial P}$ Indicates the slope of the demand curve; In general, the demand and the price change in the opposite direction, so there is a "-" sign in the formula, which means that when the price rises, the demand decreases, and vice versa, when the price falls, the demand increases. P1 and P2 represent the lowest and highest prices of Tesla Model 3/Y series from 2018 to 2020, respectively, and Q1 and Q2 represent the sales volume of Model 3/Y at P1 and P2, respectively. The data after Tesla set up a factory in China and started mass production were substituted into the formula for calculation and linear regression analysis (Pearson analysis) to obtain R2 $=0.987$, and the sales formula of Tesla was fitted as follows: $Q=189368.061-$ $3275.804 \times$ PThe R-square value of the model is 0.987 , which means that the price can explain $98.7 \%$ of the change in sales volume. The model passed the $\mathrm{F}$ test $(\mathrm{F}$ $=292.797, \mathrm{p}=0.001<0.05)[19]$, which means that the price must have an impact on the sales volume. The final specific analysis shows that the regression coefficient of the price is $-3275.804(\mathrm{t}=-17.111, \mathrm{p}=$ $0.001<0.01)$.

$$
\mathrm{Ed}=-(-3275.804) \times \frac{(23.59+55) / 2}{(13315.5+110640.25) / 2}=2.077
$$

$2.077>1$ indicates that Tesla's Model 3/Y, two mass-produced models in the Chinese market, are price elastic in demand, meaning that price will significantly 
impact sales [19]. The fitting conclusion shows that the demand will increase by $2.077 \%$ when the price falls by $1 \%$. As the representative of the electric vehicle industry, Tesla is different from Deng Ting through the price elasticity performance of Tesla. Yan Junjie concluded in 2015 that electric vehicles do not have a price elasticity of demand. That is, price is a significant factor affecting consumers buying electric vehicles. This price elasticity performance proves that for Tesla, in the price reduction stage of skimming pricing, the price has greatly contributed to the increase of sales.

\subsection{Application of skimming pricing}

When Tesla produced its first car in February 2008, Tesla deliberately chose seven elites from Silicon Valley as its first customers, including Google founders Larry Page and Sergey Brin. Jeff Skoll of eBay. This is a milestone in Tesla's history. The delivery of these seven Roadsters quickly created Tesla's trendy and high-end image in the public mind and gave Tesla's user portrait: high-end, love of environmental protection, love of technology, trendy. With such a marketing start and precise customer positioning, Tesla soon had many fans. Tesla has become a carrier for users to express their identity and image. Then it gradually gained a foothold in the North American market, accelerated its development, and became the leader of electric vehicles. At this stage, the price range of Tesla's Roadster electric vehicle is between $\$ 100000$ and $\$ 170000$, which is comparable to Porsche 911 in the United States at the same time. It belongs to the price category of luxury cars. Today, Model X and Model Y are still priced in the luxury car range. During this period, the high price brought about the return of funds and established the public's first impression of Tesla, which greatly enhanced the brand power and product transfer value. This is the high pricing stage of Tesla.

In the second stage of Tesla's price, Tesla planned a Chinese factory in 2016 and officially put it into production in 2019. By the end of July 2021, the starting price of Model 3 had dropped from 550,000 at the beginning of its launch in 2018 to 235,900 . It took only three years for the price to be cut in half. Throughout the automobile market, such a large price reduction is rare. According to the analysis in Section 3.2, for every $1 \%$ decrease in price, the demand will increase by 2 . Under the price elasticity data of $077 \%$, Model 3 's price reduction strategy has become a magic weapon to open up the Chinese market. In this process, it is worth mentioning that the $\mathrm{O} 2 \mathrm{O}$ model is an important sales model for Tesla. The high-end image established by Tesla at the high price stage has given customers a huge benefit in terms of consumer image recognition. It is the image value in the four basic value elements of product value, personnel value, service, and image. In this category, the standardized regression equation of overall satisfaction is:

Overall satisfaction $\mathrm{Y}=0.223 * \mathrm{X} 1+2.012 * \mathrm{X} 2+$

$0.441 * \mathrm{X} 3+0.253 * \mathrm{X} 4+0.362 * \mathrm{X} 5+0.633 * \mathrm{X} 6-$

10.911

The impact factor of image value is 0.253 [20].

Because Tesla's price reduction directly reduces Tesla's total customer cost to a great extent, according to the formula of "delivered value = total customer valuetotal customer cost" [4], Tesla's customer satisfaction can be greatly improved. When the perceived value is greater than the expected value, customers are highly satisfied and feel happy. In addition, the benefit of image value to transfer value magnifies the demandsupply effect, which makes Tesla's sales successfully rank at the forefront of the market in this price reduction stage. In June 2020, Tesla Model 3 won first place in global sales with 35900 vehicles, and the cumulative sales of Tesla Model 3 in January-June also ranked first. It is also the only model with a cumulative sale of more than 100000 vehicles.

In this process, we can regard Tesla's price strategy as like Tesla's marketing strategy. From the keyword search of the Internet, apart from the huge discussion and news reports brought about by Tesla CEO's Twitter price reduction, there is almost no real advertising, which shows that the price reduction is far beyond the price reduction itself. Its sensational advertising effect and more transfer value are the fundamental reasons for its sales expansion and market share rise.

\subsection{Motivation and Background Analysis of Tesla's Price Reduction Strategy}

Although Tesla, as the leading brand of electric vehicles, has a great influence globally, it is not optimistic in the early Chinese market. According to the sales data of Tesla in the first three quarters of 2015, the number of Tesla deliveries in China in 2015 will not exceed 5000. The huge Chinese market contrasts with the small contribution rate. Among them, Tesla's high price and imperfect infrastructure in the early Chinese market were the main factors that hindered sales. Tesla's early pricing in the Chinese market was based on the pricing in the US market, but due to high transportation costs and various taxes and fees to enter the Chinese market, Tesla's pricing after entering the Chinese market was often high. At the same time, due to the objective reasons of electric vehicles, their production costs are often much higher than similar fuel vehicles. Although Tesla has gained the image label of luxury and high-end in China and has a unique attraction for some consumers, the high price still becomes a barrier to limit the release of purchasing power of the main consumers in the market. Throughout the history of automobile development, Luxury brands such as Bentley, Bugatti and Lamborghini were eventually acquired by 
Volkswagen Group, and Ferrari became the pride of Fiat Group. Thus, relying solely on the high-end market in the current market conditions, it is impossible to succeed in becoming the world's first car company, so Tesla to open the situation, the price reduction will be a feasible way. The incumbent refers to the company that occupied China's domestic traditional and electric vehicles before Tesla entered the domestic market. When Tesla entered the domestic market, it used its technological advantages to gradually occupy a larger market share by reducing the price of electric vehicles, forcing the incumbent to spend more time and cost on electric vehicle technology research. At the same time, it also forces other electric vehicle companies to reduce prices together. In the past, the direction of capacity expansion of incumbents was mainly the simple upgrade of old models. In the new competitive environment of multi-variety, multi-batch and differentiation, this strategy has lost its existing advantages, but in the short term, it has fallen into the dilemma of insufficient innovation, fewer brand reserves and high inventory pressure. This also provided an advantage for Tesla to quickly occupy the electric vehicle market.

\subsection{Reasons for Price Elasticity of Tesla Demand}

First, through the research of this paper, Tesla's automobile products have great price elasticity. Unlike the research conclusion before 2015, the reason may be that before 2015, the price of electric vehicles is generally high, and Tesla has not yet achieved domestic production. At the same time, unlike traditional vehicles, electric vehicles have not yet been widely popularized, and electric vehicles are still in the fresh period of the market. Consumers who are willing to try to buy and use electric vehicles often already own traditional cars and have a taste for buying electric vehicles. At the same time, the consumer surplus of this consumer group is high, and they can afford a larger expenditure. For such a group, the price is often not the first factor they consider, and the quality of the car is the main consideration for them to buy or not [21]. But after 2015, Tesla's Chinese factory began production. The concept of electric vehicles has been bred and matured in China. It is no longer a novel and trendy concept but a common commodity in life like a gasoline car. This also means that the sinking of the electric vehicle market will start to replace the gasoline vehicle market. As a result, electric vehicles gradually have the same commodity attributes as gasoline vehicles and begin to homogenize from commodity classification. Therefore, Tesla has a price elasticity of demand after 2015, which is also consistent with the conclusion of our study.

\section{CONCLUSION}

\subsection{Entry prevention effect of Tesla's price strategy}

As shown in Figure 1, in price reduction, the sales volume of Tesla electric vehicles is also gradually increasing. In the early stage, Tesla uses skimming pricing to recover costs through high prices quickly. In the mature stage of products, Tesla steadily reduces prices and uses high cost-effective pricing to attract consumers to buy Tesla electric vehicles, thus defining the target consumer groups. This price strategy has helped Tesla capture a larger share of the market for electric vehicles.

On July 30,2021 , the price of the upgraded version of Tesla's standard endurance was lowered by 15000 yuan again, and the adjusted price started at 235900 yuan. Meanwhile, on July 8, Tesla lowered the threshold of Model Y made in China by 70000 yuan to 276000 yuan. Because of the excessive price reduction and the high performance-price ratio, many consumers are attracted to order Tesla in July 2021, and will wait until October to get the car. The sales of Model Y are booming. This is also in line with the previous analysis and judgment of Tesla's price elasticity of demand. On July 27th, Tesla released its second-quarter earnings after the US market. According to the report, Tesla's revenue in the second quarter was about $\$ 11.96$ billion, up about $98 \%$ year-on-year, and its GAAP net profit attributable to ordinary shareholders was about $\$ 1.14$ billion, nearly ten times that of the same period last year. For the first time, the company's net profit exceeded \$1 billion. Among them, Tesla's automotive business revenue during the reporting period was about $\$ 10.21$ billion, an increase of about $97 \%$ over the same period last year, and the GAAP gross profit rate of automobiles in the second quarter also increased from $25.4 \%$ in the same period last year to $28.4 \%$. Among them, Model 3, and Model Y account for most new cars. At the same time, according to the National Bureau of Statistics, since 2021, the cumulative growth rate of new energy vehicle production in China has remained above $200 \%$, and the cumulative growth rate of new energy vehicle production in June reached 205\%. The Chinese market accounts for $30 \%$ of Tesla's global market. Since Tesla entered China, it has taken less than five years to grow 15 times from $2 \%$ to $30 \%$. Therefore, Tesla's price reduction strategy has helped Tesla to expand its share of the new energy vehicle market in China. At the same time, it is expected to occupy more market share of electric vehicles and further enhance its sales of automobile business under the good overall development trend of new energy vehicles in China.

In this process, Tesla has made a successful breakthrough in the face of local automobile manufacturers such as BYD, Weilai, Ideal and other 
former incumbents. Among them, Tesla's demand price elasticity plays a huge role, and according to the price trend of local incumbents, it has obvious defensive characteristics. The sudden and preemptive price reduction of Tesla caught the incumbent by surprise, thus successfully completing the breakdown and occupation of the Chinese market. Tesla still maintained a relatively high growth rate when there was a lot of negative news. Based on the above data, Tesla has achieved a strong entry effect by the significant price elasticity of demand for electric vehicles.

\subsection{Outlook for the future}

According to the three-step strategy proposed by Musk in his early years. Tesla's Model 3 will continue to be priced lower. Compared with Ford's Model T, which was born in 1908, Tesla's Super Factory can correspond to the great assembly line of Model T. The market positioning of Model 3 is undoubtedly a copy of Model $\mathrm{T}$, that is, a car that goes into millions of households. With the gradual expansion and improvement of the Tesla Super Factory in Shanghai and the disclosure of a document between Tesla and the Shanghai Municipal Government, the Super Factory will have to pay 2.23 billion yuan in taxes annually from the end of 2023. If this condition cannot be met, the corresponding land must be returned. At the same time, Tesla must also invest RMB 140 in the Shanghai plant in the next five years. Capital expenditure of 800 million yuan. Therefore, it is imperative to continue to expand production and reduce prices in the foreseeable future. It is boldly predicted that the price of Model 3 is likely to fall below 200000. Or from the perspective of models, Tesla will introduce new models with lower prices.

\subsection{Tesla's Price Strategy Can Be Used for Reference by Other Car Companies}

Through the analysis of this paper, we can get a different conclusion from the price analysis of electric vehicles before 2015. Electric vehicles have changed from a commodity lacking price elasticity of demand to a commodity with price elasticity of demand like traditional vehicles, and consumers are very sensitive to the price of electric vehicles. Then price reduction will become a major weapon to expand the market.

At present, there are many new forces of electric vehicles in China, such as Weilai, Ideal, Xiaoping and BYD. By comparing with Tesla's development path. These car companies should first vigorously develop technology and improve sales models to create space for price exploration. Then, after the completion of the technological revolution and after-sales innovation, we can use the weapon of price elasticity of demand to occupy market share. At the same time, Tesla's service in China has always been criticized, and other car companies have seized Tesla's weakness to make up for its shortcomings and strengthen their attacks to compete for the market.

\section{REFERENCES}

[1] Shang Kui. Research on the Price Strategy of W Motor Company in China Market [D]. HowNet, 2020 .

[2] Notice of the National Development and Reform Commission on the Pilot Project of Subsidies for Private Purchase of New Energy Vehicles (Cai Jian [2010] No.230)

[3] Philip Kotler, Gary Armstrong. Principles of Marketing

[4] Consumer Behavior, Western Michigan University

[5] Jack Trout, Positioning: The Way to Compete in the Age of Homogenization, 1969

[6] Marketing Management (13th Edition) was published by Renmin University of China Press in April 2009 by Philip Kotler, Kevin Lane Keller and Lu Taihong. ISBN9787300104591

[7] Jerome McCarthy, Basic Marketing, 1960

[8] Robert Lauterbon, Integrated Marketing Communications

[9] Masson, R. T. , Shaanan, J. Excess Capacity and Limit Pricing: An Empirical Test[J]. Economica, 1986, 53( 211) :365-378.

[10] Fudenberg, D. , Tirole, J. Preemption and Rent Equalization in the Adoption of a New Technology [J]. Review of Economic Studies, 1985, 52(3) : 383-401.

[11] Yang, S. S. , Anderson, E. J. Competition Through Capacity Investment Under Asymmetric Existing Capacities and Costs [J]. European Journal of Operational Research, 2014, 237(1) : 217-230

[12] Deng Ting; Yan Junjie's Research on the Development Countermeasures of New Energy Vehicles from the Perspective of Demand Price Elasticity 20155

[13] Hamish Mackenzie. Tesla: Achieving the Impossible [M]. First edition in May 2019. CITIC Publishing Group Co., Ltd., May 2019.

[14] Huang Xuming Research on Marketing Strategy of Tesla Motors in China CNKI 2016

[15] Jiang Shengjun. Empirical research on the development of electric vehicle market from the perspective of purchase intention. HowNet, 2017.

[16] Qi Fangming Research on Marketing Strategy of 
Tesla Automobile Brand in China, CNKI 2020

[17] The SPSS project (2021). SPSS. (Version 21.0)

[18] Sun Dao-de. Selection of the Linear Regression Model According to the Parameter Estimation[J]. Wuhan University Journal of Natural Sciences, 2000, 5(4):400-405.

[19] Barassi M R. Microeconometrics; Methods and Applications by A. Colin Cameron; Pravin K.
Trivedi[J]. 2005.

[20] Yu Jing. Research on Market Status and Marketing Strategy of New Energy Vehicles [D]. HowNet, 2016.

[21] Lan Xiaojie, Yao Lei, Research on Customer Satisfaction Index System of Wushuai Automobile 